\title{
Adenoid cystic carcinoma of the parotid metastasising to the dura fifteen years post primary resection: A case report
}

\author{
(D) Gulpembe Bozkurt, ${ }^{1}$ (1) George Jayan, ${ }^{2}$ (D) Abdullah Soydan Mahmutoglu ${ }^{3}$ \\ ${ }^{1}$ Department of Otolaryngology, Acibadem University Hospital, Istanbul, Turkey \\ 2Department of Hepatobiliary Surgery, Northern General Hospital, Sheffield, UK \\ ${ }^{3}$ Department of Radiology, Istanbul Training and Research Hospital, Istanbul, Turkey
}

\begin{abstract}
Adenoid cystic carcinoma (ACC), regardless of the primary site, is typically characterized by a long clinical course associated with a high rate of distant metastases. Intracranial metastasis of ACC is a very rare entity with only few reported cases in the literature. In this study, we report an unusual case of extra-axial intracranial metastasis of ACC in the dura. The primary parotid gland tumour was resected 15 y back. No recurrence had been detected before the occurrence of extra-axial metastasis. After surgical decompression, palliative radiotherapy was administered. To our knowledge, this is the longest interval for the development of metastases following excision of a parotid adenoid cystic carcinoma. This case can raise awareness across specialties that patients with adenoid cystic carcinoma are still at risk of developing metastases even following specialist discharge.
\end{abstract}

Keywords: Adenoid cystic carcinoma; brainstem compression; distant metastasis; extra-axial intracranial metastasis; perineural invasion.

Cite this article as: Bozkurt G, Jayan G, Mahmutoglu AS. Adenoid cystic carcinoma of the parotid metastasising to the dura fifteen years post primary resection: A case report. North Clin Istanb 2020;7(3):294-297.

A cour denoid cystic carcinoma (ACC) is a rare tumour, accounting for approximately $1 \%$ of all head and neck malignancies and approximately $10 \%$ of all tumours of the salivary glands [1]. The tumour generally progresses slowly and tends to develop wide perineural invasions of the adjacent nerves, significantly increasing the risks of local recurrence and spread among neural routes. ACC is also characterized by a long clinical course associated with a high rate of distant metastasis (33-50\%), even after locoregional control has been achieved [2]. Haematogenous metastasis is more common than lymphatic metastasis, especially to the lungs, bones, and liver [3].

Intracranial extra-axial metastasis after ten years has been reported and some institutions follow patients up for a longer period. After this period, most patients are left in the care of primary care physicians who may not be aware of this reported complication.

In this study, we present a rare case of intracranial extra-axial metastasis developing fifteen years after $\mathrm{cu}$ rative surgery to treat an ACC of the parotid gland. The primary therapy, metastasis, and outcome are discussed.

\section{CASE REPORT}

A 70-year-old female presented with a left facial lower motor neurone and mild right-sided hemiparesis of two weeks duration to her family doctor. Medical history includes ACC of the left parotid with perineural invasion,

Received: September 09, 2018 Accepted: March 28, 2019 Online: April 07, 2020

Correspondence: Dr. Gulpembe BOZKURT. Acibadem Universitesi Hastanesi, Kulak Burun Bogaz ve Bas Boyun Cerrahisi Klinigi, Halkali Merkez Mahallesi, Halkali Altinsehir Istanbul Cad. No: 16, 34303 Kucukcekmece, Istanbul, Turkey.

Tel: +90 2124044444 e-mail: gptalayhan@gmail.com

(c) Copyright 2020 by Istanbul Provincial Directorate of Health - Available online at www.northclinist.com 

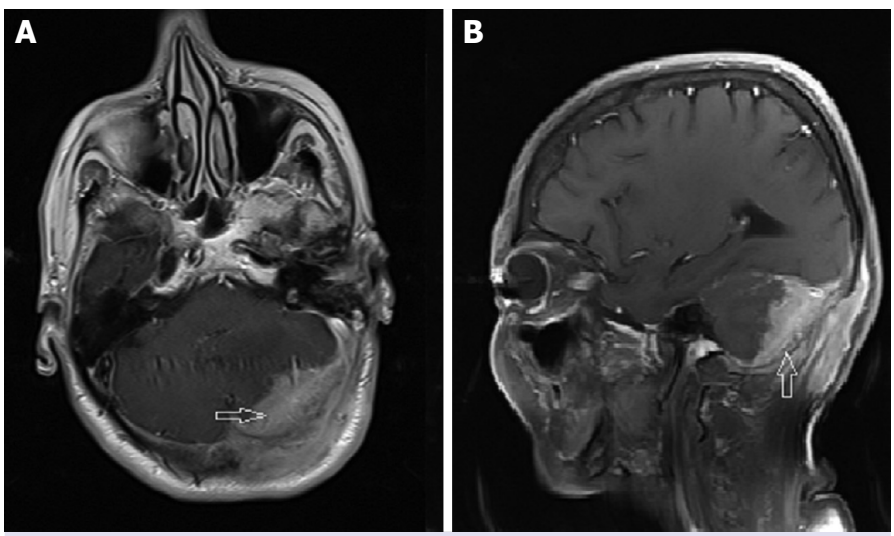

FIGURE 1. Axial (A) and sagittal (B) sections of T1-enhanced MRI showing a large extraaxial enhancing mass in the left hemioccipital space of the cranium.

which was treated with a left parotidectomy with lymph node clearance and adjuvant radiotherapy fifteen years previous and hypertension. There is no relevant family history.

On examination, there was evidence of a left facial lower motor neurone lesion with House-Brackmann grade 6 and a mild right-sided hemiparesis, but no other abnormality was detected on neurological examination.

T1-enhanced magnetic resonance imaging (MRI) revealed invasive destruction of the left hemi-occipital calvarium, a large extra-axial enhancing mass in the posterior fossa, and an extra-axial soft tissue extension. The lesion had also infiltrated the adjacent extracranial muscles (Fig. 1).

The multidisciplinary team decided the best course of action would be radical surgical resection under neurosurgery. Given that this could be an astrocytoma or intracranial metastasis, the patient underwent sub-occipital craniectomy with excision of the tumour mass.

At the time of surgery, a frozen-proven metastatic ACC was found to have destroyed the left occiput and to exhibit an intracranial epidural extension. The cerebellar tissue was intact. The resection stump was tumourpositive; a portion of the tumour could not be resected because of bleeding from the portions of the sigmoid and transverse sinuses that the tumour had invaded.

An ACC with a cribriform pattern of basaloid cells surrounded by pseudocysts of varying sizes was evident on histopathological evaluation. Immunohistochemistry (IHC) revealed membranous/cytoplasmic staining for cluster differentiation (CD) - 117 (c-KIT), a recently recognized marker of ACC [4], which is also being evaluated for targeted therapy in some phase II trials [5] (Fig.

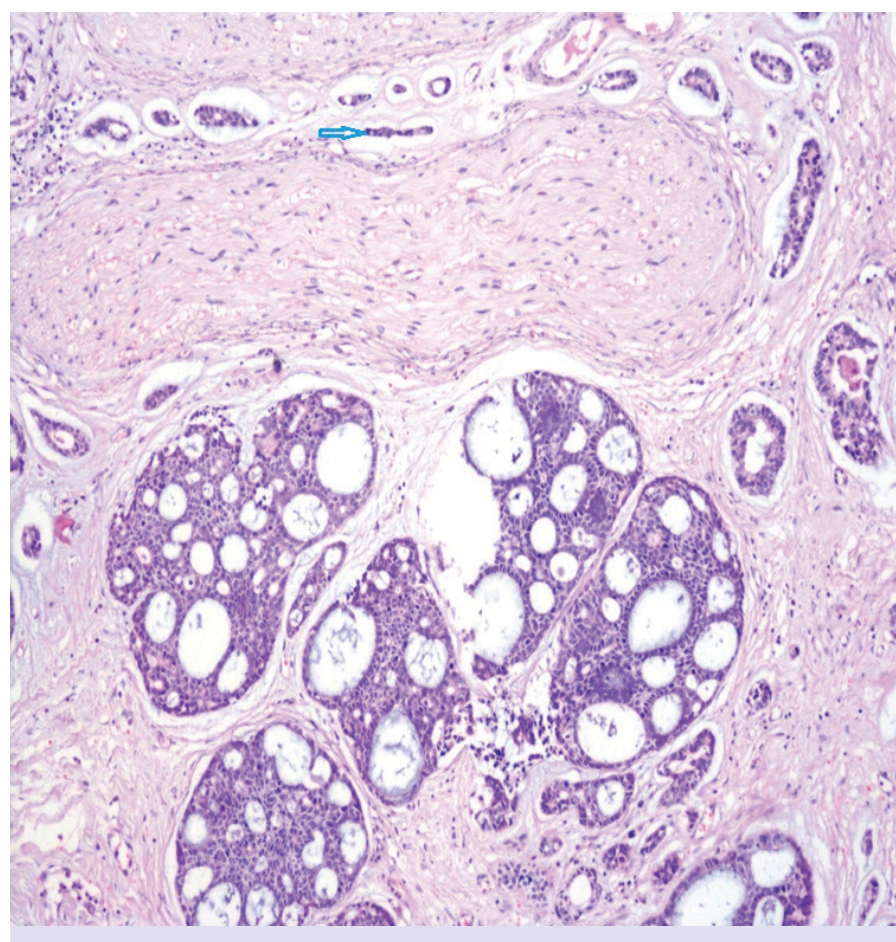

FIGURE 2. A photomicrograph showing small dark-stained cells with scanty cytoplasm arranged in nests fenestrated by round or oval spaces (the cribriform pattern) and perinerineural invasion (arrow) hematoxylin and eosin ( $\times 100)$.

2). IHC staining also demonstrated nests of p63-positive tumour cells, indicating a poorly differentiated carcinoma containing a myoepithelial component (Fig. 3).

Two weeks after surgery, palliative radiotherapy was commenced to the resection cavity and residual tumour. The patient was discharged from the hospital after twenty days. With three months post-treatment, her paresis improved, and she is currently undergoing routine followup and MRI scanning and is under the care of oncology and neurosurgery. Informed consent to the publication of information about her was approved by the patient.

\section{DISCUSSION}

Metastasis to the intracranial extra-axial space is extremely rare in ACC although some cases with extra-axial, intracranial, metastatic ACCs have been reported in the literature $[6,7]$. These metastases were detected up to a maximum of 5.5 years after surgery. To our knowledge, our patient's interval of fifteen years is the longest reported.

The "gold-standard" treatment for ACC is radical surgical resection with tumour-free margins; postoper- 


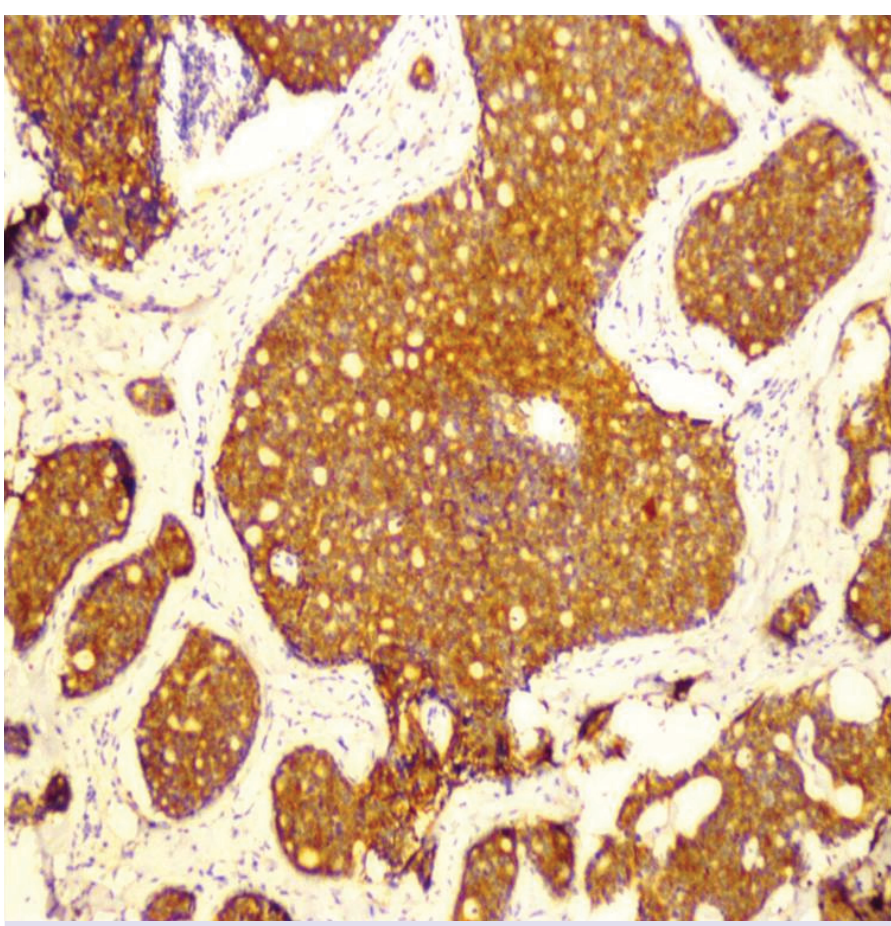

FIGURE 3. A photomicrograph showing immunoreactivity with CD-117 ( $\times 100)$.

ative radiotherapy is an effective adjuvant treatment for residual microscopic disease located on adjacent nerve branches [8]. Because many ACC tumors have slow growth kinetics, they show consistently low response rates to cytotoxic chemotherapy for metastatic disease. Moreover, trials of targeted therapy (c-KIT, EGFR, HER-2) to date have not yet identified an agent with sufficient activity to be deemed standard in the treatment of advanced ACC as well [5].

Distant metastases are unpredictable, developing regardless of complete locoregional control. Factors predictive of such metastases have been suggested to be cervical node involvement, a tumour diameter $>3 \mathrm{~cm}$, solid histological subtype. The role of locoregional recurrence in distant metastasis is not obvious [9]. Our patient had negative surgical margins in the first operation. Surprisingly, the tumour of our patient exhibited a cribriform growth pattern rather than a solid pattern. However, her immunohistochemistry staining was positive for $\mathrm{c}-\mathrm{KIT}$ (CD-117) which has been linked to biologic aggressiveness and poor prognosis [10]. She was also found to have perineural involvement at first, which increases the risk of recurrence, and could account for $14 \%$ to $22 \%$ of patients with head and neck ACCs who develop intracranial tumor extension [11].
The route of tumour spread from the parotid gland to the dura remains unclear. The perineural space is relatively free of host defences and affords the path of least resistance for malignant cells. Perineural invasion is diagnosed by the detection of tumour cells in perineural nerve spaces in patients with malignancies; this means that tumour cells can leave the original site by extending along nerves. The cancer is thus continuous with the primary tumour along the perineural spaces of the peripheral nerves, eventually reaching the central nervous system. In head and neck cancers, tumours often spread along major nerves, which thus serve as pathways to intracranial extensions. Most commonly, the trigeminal and facial nerves are affected because both feature widespread fibre networks in the head and neck area [12]. The facial nerve is most commonly affected by tumors arising from the parotid gland (adenoid cystic carcinoma, acinic or mucoepidermoid carcinoma) [13]. An ACC of the parotid gland may more readily invade the intracranial space than other ACCs; the parotid gland is rich in neurovascular structures and is directly connected to the intracranial cavity via the infratemporal fossa [14].

\section{Conclusion}

ACC is generally recognized for its typical indolent behavior of late-onset locoregional recurrences (years) and frequent and often silent diagnosis of distant metastases. Thus, any symptomatic presentation of a distant ACC metastasis may be an extensively delayed diagnosis, as in the present case. From this point of view, the following issues should be kept in mind:

- Consider extending the follow-up period of patients with ACC for more than ten years.

- Clinicians should be aware of ACC metastases postten-year resection.

- New-onset neurological symptoms in a patient with a history of parotid ACC should be investigated urgently.

- A high index of suspicion for brain metastases should be with patients presenting with neurological symptoms with a history of parotid ACC.

Informed Consent: Written informed consent was obtained from the patient for the publication of the case report and the accompanying images.

Conflict of Interest: No conflict of interest was declared by the authors. 
Financial Disclosure: The authors declared that this study has received no financial support.

Authorship Contributions: Concept - GB, GJ, ASM; Design - GB, GJ, ASM; Supervision - GB, GJ, ASM; Fundings - GB, ASM; Materials - GB, GJ; Data collection and/or processing - GB, GJ, ASM; Analysis and/or interpretation - GB, GJ, ASM; Literature review - GB, GJ, ASM; Writing - GB, GJ, ASM; Critical review - GJ, ASM.

\section{REFERENCES}

1. Dodd RL, Slevin NJ. Salivary gland adenoid cystic carcinoma: a review of chemotherapy and molecular therapies. Oral Oncol 2006;42:75969. [CrossRef]

2. Sung MW, Kim KH, Kim JW, Min YG, Seong WJ, Roh J, Let al. Clinicopathologic predictors and impact of distant metastasis from adenoid cystic carcinoma of the head and neck. Arch Otolaryngol Head Neck Surg 2003;129:1193-7. [CrossRef]

3. Kokemueller H, Eckardt A, Brachvogel P, Hausamen JE. Adenoid cystic carcinoma of the head and neck--a 20 years experience. Int J Oral Maxillofac Surg 2004;33:25-31. [CrossRef]

4. Mino M, Pilch BZ, Faquin WC. Expression of KIT (CD117) in neoplasms of the head and neck: an ancillary marker for adenoid cystic carcinoma. Mod Pathol 2003;16:1224-31. [CrossRef]

5. Dillon PM, Chakraborty S, Moskaluk CA, Joshi PJ, Thomas CY. Adenoid cystic carcinoma: A review of recent advances, molecular targets, and clinical trials. Head Neck 2016;38:620-7. [CrossRef]
6. Lee YY, Castillo M, Nauert C. Intracranial perineural metastasis of adenoid cystic carcinoma of head and neck. J Comput Tomogr 1985;9:219-23. [CrossRef]

7. Terasaki M, Tokutomi T, Maruiwa H, Sugita Y, Harada H, Shigemori M. High-grade adenoid cystic carcinoma originating from the lacrimal gland. Brain Tumor Pathol 2000;17:159-63. [CrossRef]

8. Vander Poorten VLM, Balm AJM, Hilgers FJM. Management of cancer of the parotid gland. Curr Opin Otolaryngol Head Neck Surg 2002;10:134-44. [CrossRef]

9. van Weert S, Reinhard R, Bloemena E, Buter J, Witte BI, Vergeer MR, et al. Differences in patterns of survival in metastatic adenoid cystic carcinoma of the head and neck. Head Neck 2017;39:456-63. [CrossRef]

10. Azumi N, Battifora $H$. The cellular composition of adenoid cystic carcinoma. An immunohistochemical study. Cancer 1987;60:1589-98.

11. Kazumoto K, Hayase N, Kurosumi M, Kishi K, Uki J, Takeda F. Multiple brain metastases from adenoid cystic carcinoma of the parotid gland. Case report and review of the literature. Surg Neurol 1998;50:475-9.

12. Frunza A, Slavescu D, Lascar I. Perineural invasion in head and neck cancers - a review. J Med Life 2014;7:121-3.

13. Lee C, Given II CA. Evaluation of retrograde tumor spread to facial nerve (VII) and relation to trigeminal nerve (V). Paper presented at: Annual meeting of the American Society of Neuroradiology. San Diego; 1999.

14. Ferrari M, Schreiber A, Mattavelli D, Lombardi D, Rampinelli V, Doglietto F, et al. Surgical anatomy of the parapharyngeal space: Multiperspective, quantification-based study. Head Neck 2019;41:642-56. 